\title{
Alternatif Perencanaan Perkerasan Jalan Ruas Maros - Ujung Lamuru dengan Metode Bina Marga 2013
}

\author{
Monalisa Bumbungan \\ Dosen Program Studi Teknik Sipil, Universitas Kristen Indonesia Paulus, Makassar, Indonesia \\ monalisa08@yahoo.com
}

\begin{abstract}
ABSTRAK
Penelitian ini bertujuan untuk mendapatkan tebal perkerasan lentur (Flexible Pavement) dari metode Bina Marga 2013. Metode Bina Marga 2013 merupakan metode yang didesain oleh Direktorat Jendral Bina Marga, Departemen Pekerjaan Umum. Perubahan metode Bina Marga menjadi metode Bina Marga 2013 dimaksudkan agar umur rencana perkerasan jalan lebih lama. Pada ruas Jalan Maros-Ujung Lamuru sebelumnya telah memiliki lapisan perkerasan dimana perencanaan yang lama menggunakan metode Analisa Komponen dan penulis merencanakan dengan menggunakan metode Bina Marga 2013. Dari hasil perhitungan perencanaan tebal perkerasan jalan ruas Maros - Ujung Lamuru, pada segmen 9 perlu adanya peningkatan LPB setebal $150 \mathrm{~mm}$ atau $15 \mathrm{~cm}$ karena nilai $C B R$ tanah dasarnya rendah. Tebal perkerasan dengan menggunakan Metode Bina Marga 2013 lebih ekonomis dan umur rencananya lebih lama dibandingkan dengan metode Analisa Komponen.
\end{abstract}

Kata Kunci: Perkerasan Lentur, metode Bina Marga 2013

\begin{abstract}
This study aims to obtain the thickness of the flexible pavement (Flexible Pavement) from the Bina Marga 2013 method. The Bina Marga 2013 method is a method designed by the Directorate General of Highways, Ministry of Public Works. The change in the Bina Marga method to the Bina Marga 2013 method is intended to make the road pavement plan last longer. The Maros-Ujung Lamuru road section previously had a pavement layer where the old planning used the Component Analysis method and the author planned using the 2013 Bina Marga method.From the results of calculating the pavement thickness planning for the Maros - Ujung Lamuru section, segment 9 needs an increase in LPB $150 \mathrm{~mm}$ or $15 \mathrm{~cm}$ thick because the CBR value of the ground is low. Pavement thickness using the Bina Marga 2013 method is more economical and has a longer plan life than the Component Analysis method.
\end{abstract}

Keywords: Flexible Pavement, Bina Marga method 2013

\section{PENDAHULUAN}

Perkerasan lentur (Flexible Pavement), yaitu perkerasan yang menggunakan aspal sebagai bahan pengikat. Lapisan-lapisan perkerasannya bersifat memikul dan menyebarkan beban lalulintas. Struktur perkerasan jalan terdiri dari beberapa lapis material yang diletakkan pada tanah dasar. Komponen material tersebut akan memberikan sokongan penting dari kapasitas struktur perkerasan. Untuk mendapatkan kekuatan struktur perkerasan yang optimal dan ekonomis, maka struktur perkerasan dibuat berlapis-lapis berdasarkan besar beban yang diterima dari roda kendaraan sampai ke tanah dasar. Setiap lapis pada perkerasan mempunyai fungsi yang berbeda-beda. Setiap lapisan juga harus bisa mendistribusikan beban sampai ke bawah, jika salah satu lapisan tidak bisa mendistribusikan beban dengan baik, maka akan merusak lapisan yang lain. Lapisan paling atas terdiri dari 2 lapisan, yaitu: wearing course, kemudian binder course, lalu lapisan pondasi atas (base course), lapisan pondasi bawah (sub-base), kemudian tanah dasar (sub-grade). Pada ruas Jalan Maros-Ujung Lamuru sebelumnya telah memiliki lapisan perkerasan dimana perencanaan yang lama menggunakan metode Analisa Komponen dan penulis merencanakan dengan menggunakan metode Bina Marga 2013. Lingkup metode Bina Marga 2013 meliputi desain perkerasan lentur dan perkerasan kaku untuk jalan baru, pelebaran jalan dan rekonstruksi. Komparasi metode Bina Marga 2013 dengan metode Bina Marga sebelumnya yaitu metode Bina Marga sebelumnya memiliki umur rencana maksimal 10 tahun, dan metode Bina 
Paulus Civil Engineering Journal

Jurnal Teknik Sipil UKI-Paulus Makassar https://doi.org/10.52722/pcej.v3i2.3217
Volume 3 No.2, Juni 2021

e-ISSN 2775-4529

p-ISSN 2775-8613
Marga 2013 memiliki umur rencana lebih lama yaitu 20 tahun. Metode Bina Marga 2013 ini menjelaskan faktor-faktor terkait pemilihan struktur perkerasan jalan seperti pendetailan desain, drainase dan persyaratan konstruksi. Metode desain perkerasan jalan ini digunakan untuk menghasilkan desain awal yang hasilnya kemudian diperiksa terhadap pedoman desain perkerasan Pd T-01-2002-B, dan Software Desain Perencanaan Jalan Perkerasan Lentur (SDPJL) untuk desain perkerasan lentur, dan dengan $\mathrm{Pd}$ T-14-2003 untuk desain perkerasan kaku. Meode ini dapat membantu dalam meyakinkan kecukupan struktural dan kepraktisan konstruksi untuk kondisi beban dan iklim Indonesia. Sebagai konsekuensinya saat memvalidasi kecukupan struktural, sangat penting untuk menguasai elemen kunci tertentu dari metode desain ini. Prosedur validasi menggunakan ketentuan umur rencana, beban, iklim, tanah dasar lunak, serta batasan konstruksi, dan dilakukan dengan penuh pertimbangan dan kehati-hatian.

\section{METODOLOGI PENELITIAN}

\section{Tahapan penelitian}

Tahapan penelitian yang dilakukan dapat dilihat pada Gambar 1 berikut:

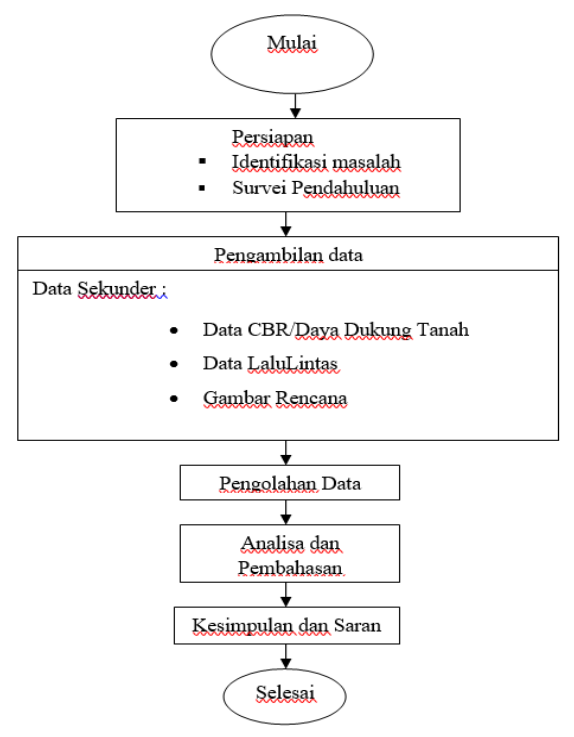

Gambar 1. Bagan Alir Penelitian

\section{Metode Pengambilan Data}

Data yang dikumpulkan dalam penelitian ini yaitu berupa data sekunder mengenai perencanaan perkerasan jalan yang meliputi data $C B R /$ daya dukung tanah, data lalu lintas, dan gambar rencana, data diperoleh dari Dinas PU Bina Marga.

\section{Pengolahan data}

Berdasarkan data yang dikumpulkan maka pengolahan data yang dilakukan secara umum sampai dengan tahapan perencanaan perkerasan lentur jalan dengan Metode Bina Marga 2013.

\section{Analisis Data}

Hasil perencanaan dalam bentuk tabel yang ditampilkan dengan hasil perencanaan sebelumnya. Pembahasan yang dilakukan yaitu mengenai perbedaan dari hasil perencanaan tebal perkerasan lentur dengan dua metode yaitu Metode Analisa Komponen dan Metode Bina Marga 2013.

\section{ANALISIS DAN PEMBAHASAN}

Data dan Analisis Perkerasan Lentur

\section{CBR Tanah Dasar}

Solusi desain pondasi jalan berdasarkan nilai $C B R$ desain yang telah diperoleh untuk mengetahui perlu tidaknya peningkatan tanah dasar. Hasil dapat dilihat pada tabel 1

Tabel 1. Penentuan Peningkatan $L P B$

\begin{tabular}{|c|c|c|}
\hline & & Lalu lintas Lajur desain \\
\hline No. & CBR tanah dasar & $\begin{array}{c}\text { Umur rencana } 40 \text { tahun } \\
\text { (juta } C E S A 5 \text { ) }\end{array}$ \\
\hline
\end{tabular}


(2-4)

Tebal minimum peningkatan

tanah dasar

$\begin{array}{ccc}1 & 6.6 \% & \text { Tidak perlu peningkatan } \\ 2 & 6 \% & \text { Tidak perlu peningkatan } \\ 3 & 5.3 \% & \text { Tidak perlu peningkatan } \\ 4 & 6.2 \% & \text { Tidak perlu peningkatan } \\ 5 & 5.6 \% & \text { Tidak perlu peningkatan } \\ 6 & 5.1 \% & \text { Tidak perlu peningkatan } \\ 7 & 6.2 \% & \text { Tidak perlu peningkatan } \\ 8 & 5.2 \% & \text { Tidak perlu peningkatan } \\ 9 & 4.1 \% & \text { Tidak perlu peningkatan } \\ 10 & 5.8 \% & \end{array}$

Dari tabel tersebut dapat diketahui bahwa pada segmen 9 perlu adanya peningkatan tanah dasar dengan tebal $150 \mathrm{~mm}$ atau $15 \mathrm{~cm}$, dan segmen lainnya tidak perlu adanya peningkatan tanah

2. Perencanaan Lalu lintas dasar.

Perhitungan LHR dan perhitungan nilai ESA dapat dilihat pada tabel 2 dan 3.

Tabel 2. Hasil Perhitungan LHR

\begin{tabular}{|c|c|c|c|c|c|c|c|c|}
\hline NO. & $\begin{array}{c}\text { Tipe } \\
\text { Kendaraan }\end{array}$ & $\begin{array}{l}\text { Trafik } \\
\text { Harian } \\
2010\end{array}$ & $\begin{array}{l}\text { Pertum- } \\
\text { buhan }\end{array}$ & $\begin{array}{c}\text { Trafik } \\
\text { Harian } \\
2013\end{array}$ & $\begin{array}{l}\text { Pertum- } \\
\text { buhan }\end{array}$ & $\begin{array}{c}\text { Trafik } \\
\text { Harian } \\
2033\end{array}$ & $\begin{array}{l}\text { Pertum- } \\
\text { buhan }\end{array}$ & $\begin{array}{c}\text { Trafik } \\
\text { Harian } \\
2033\end{array}$ \\
\hline 1 & $\begin{array}{c}\text { Sepeda } \\
\text { motor }\end{array}$ & 2718,75 & $5,00 \%$ & 3.147 & $5 \%$ & 8.351 & $5 \%$ & 8.351 \\
\hline 2 & Sedan & 108,75 & $5,00 \%$ & 126 & $5 \%$ & 334 & $5 \%$ & 334 \\
\hline 3 & Opelet & 1734,5 & $5,00 \%$ & 2.008 & $5 \%$ & 5.328 & $5 \%$ & 5.328 \\
\hline 4 & Pick up & 237 & $5,00 \%$ & 274 & $5 \%$ & 728 & $5 \%$ & 728 \\
\hline 5 & Bus Kecil & 33,25 & $5,00 \%$ & 38 & $5 \%$ & 102 & $5 \%$ & 102 \\
\hline 6 & $\begin{array}{l}\text { Bus Besar } \\
\text { Truk } 2 \\
\text { sumbu } 4\end{array}$ & 15,75 & $5,00 \%$ & 18 & $5 \%$ & 48 & $5 \%$ & 48 \\
\hline 7 & $\begin{array}{c}\text { roda } \\
\text { Truk } 2 \\
\text { sumbu } 6\end{array}$ & 50,75 & $5,00 \%$ & 59 & $5 \%$ & 156 & $5 \%$ & 156 \\
\hline 8 & $\begin{array}{l}\text { roda } \\
\text { Truk } 3\end{array}$ & 336,25 & $5,00 \%$ & 389 & $5 \%$ & 1.033 & $5 \%$ & 1.033 \\
\hline 9 & sumbu & 47,5 & $5,00 \%$ & 55 & $5 \%$ & 146 & $5 \%$ & 146 \\
\hline 10 & Truk & 0 & $5,00 \%$ & 0 & $5 \%$ & 0 & $5 \%$ & 0 \\
\hline
\end{tabular}




\begin{tabular}{|c|c|c|c|c|c|c|c|c|}
\hline & gandengan & & & & & & & \\
\hline 11 & $\begin{array}{l}\text { Truk semi } \\
\text { trailer } \\
\text { Kendaraan } \\
\text { tidak }\end{array}$ & 9,25 & $5,00 \%$ & 11 & $5 \%$ & 28 & $5 \%$ & 28 \\
\hline 12 & bermotor & 6,75 & $5,00 \%$ & 8 & $5 \%$ & 21 & $5 \%$ & 21 \\
\hline & Total & 5.299 & & 6.134 & & 16.274 & & 16.274 \\
\hline
\end{tabular}

AADT Tahun $2013=(1+0.05)^{4} \times 5.299=6.134$

AADT Tahun $2033=(1+0.05)^{20} \times 6.134=16.274$

Tabel 3. Perhitungan ESA

\begin{tabular}{|c|c|c|c|c|c|c|c|c|c|}
\hline \multirow{3}{*}{ NO. } & \multirow{3}{*}{$\begin{array}{c}\text { Tipe } \\
\text { Kendaraan }\end{array}$} & \multicolumn{5}{|c|}{ Faktor } & \multirow{3}{*}{$\begin{array}{c}\text { Faktor } \\
\text { Perusak } \\
\text { (VDF) }\end{array}$} & \multirow{2}{*}{\multicolumn{2}{|c|}{$\begin{array}{c}\text { ESA Harian rata- } \\
\text { rata }\end{array}$}} \\
\hline & & \multicolumn{2}{|c|}{ LHR TOTAL } & \multirow{2}{*}{$\begin{array}{l}\text { Distribusi } \\
\text { Kendaraan }\end{array}$} & \multicolumn{2}{|c|}{ LHR per lajur } & & & \\
\hline & & 2033 & 2033 & & 2033 & 2033 & & 2033 & 2033 \\
\hline 1 & Sepeda Motor & 8.351 & 8.351 & 0,50 & 4175 & 4.175 & 0,0000 & 0,0 & 0,0 \\
\hline 2 & Sedan & 334 & 334 & 0,50 & 167 & 167 & 0,0004 & 0,1 & 0,1 \\
\hline 3 & Opelet & 5.328 & 5.328 & 0,50 & 2664 & 2.664 & 0,1865 & $49, .9$ & 496,9 \\
\hline 4 & Pick up & 728 & 728 & 0,50 & 364 & 364 & 0,1865 & 67,9 & 67,9 \\
\hline 5 & Bus Kecil & 102 & 102 & 0,50 & 51 & 51 & 0,5536 & 28,3 & 28,3 \\
\hline 6 & Bus Besar & 48 & 48 & 0,50 & 24 & 24 & 0,1865 & 4,5 & 4,5 \\
\hline 7 & $\begin{array}{c}\text { Truk } 2 \text { sumbu } \\
4 \text { roda }\end{array}$ & 156 & 156 & 0,50 & 78 & 78 & 1,2393 & 96,6 & 96,6 \\
\hline 8 & $\begin{array}{c}\text { Truk } 2 \text { sumbu } \\
6 \text { roda }\end{array}$ & 1.033 & 1.033 & 0,50 & 516 & 516 & 1,2393 & 640,0 & 640,0 \\
\hline 9 & Truk 3 sumbu & 146 & 146 & 0,50 & 73 & 73 & 3,7080 & 270,5 & 270,5 \\
\hline 10 & $\begin{array}{c}\text { Truk } \\
\text { gandengan }\end{array}$ & 0 & 0 & 0,50 & 0 & 0 & 4,9670 & 0,0 & 0,0 \\
\hline 11 & $\begin{array}{c}\text { Truk semi } \\
\text { trailer }\end{array}$ & 28 & 28 & 0,50 & 14 & 14 & $1, .4712$ & 163,0 & 163,0 \\
\hline 12 & $\begin{array}{l}\text { Kendaraan } \\
\text { tidak bermotor }\end{array}$ & 21 & 21 & 0,50 & 10 & 10 & 0,0000 & 0,0 & 0,0 \\
\hline & Total & 16.274 & 16.274 & & 8.137 & 8.137 & & 1.768 & 1.768 \\
\hline
\end{tabular}

ESA Lalu Lintas Harian untuk 1 lajur $2033=1.768$ roda

ESA Harian untuk Awal tahun $2033=1.768$ roda

ESA Harian untuk Akhir Tahun $2033=1.768$ roda

\section{Pemilihan Jenis Perkerasan}

Jenis Perkerasan yang didapatkan dilihat pada tabel 4. 
Perkerasan kaku dengan lalu lintas berat

Perkerasan kaku dengan lalu lintas

Rendah (desa dan daerah perkotaan)

AC-WC modifikasi atau SMA dengan CTB (pangkat 5)

AC dengan CTB (pangkat 5)

$A C$ tebal $\geq 100 \mathrm{~mm}$ dengan lapis pondasi berbutir

(pangkat 5)

AC tipis atau HRS diatas lapis pondasi berbutir

Burda atau burtu dengan LPA kelas $A$ atau kerikil alam

Lapis pondasi tanah semen (soil cement)

Perkerasan tanpa penutup
4

2

$4 \mathrm{~A}$

3

3

$3 \mathrm{~A}$

3

Gambar 5

Gambar 6

Gambar 7

Tabel 4. Jenis Perkerasan

Berdasarkan nilai CESA yang diperoleh yaitu 21.863.115, maka dapat diketahui bahwa struktur perkerasannya adalah $A C$-WC modifikasi atau $S M A$ dengan $C T B$ (pangkat 5).

\section{Desain Tebal Perkerasan}

Untuk menentukan tebal lapis perkerasan berdasarkan nilai CESA. Tebal lapis perkerasan yang didapatkan yaitu:

Tabel 5. Tebal Lapisan Perkerasan

\begin{tabular}{ccc}
\hline No. & SEGMEN & TEBAL \\
\hline & & Lapisan AC-WC $4 \mathrm{~cm}$ \\
& & Lapisan AC- BC $13,5 \mathrm{~cm}$ \\
& & CTB $15 \mathrm{~cm}$ \\
& $30-40$ & LPA Kelas A $15 \mathrm{~cm}$ \\
& & CBR tanah dasar $6,6 \%$ \\
\hline & & Lapisan AC-WC $4 \mathrm{~cm}$ \\
& & Lapisan AC-BC $13,5 \mathrm{~cm}$ \\
& & CTB $15 \mathrm{~cm}$ \\
& $40-48$ & LPA Kelas A $15 \mathrm{~cm}$ \\
& & CBR tanah dasar $6 \%$ \\
& & Lapisan AC-WC $4 \mathrm{~cm}$ \\
& & Lapisan AC-BC $13,5 \mathrm{~cm}$ \\
& & CTB $15 \mathrm{~cm}$ \\
& $48-49$ & LPA Kelas A $15 \mathrm{~cm}$ \\
\hline
\end{tabular}




\begin{tabular}{|c|c|c|c|}
\hline 4 & 4 & $49-60$ & $\begin{array}{c}\text { Lapisan AC-WC } 4 \mathrm{~cm} \\
\text { Lapisan AC-BC } 13,5 \mathrm{~cm} \\
\text { CTB } 15 \mathrm{~cm} \\
\text { LPA Kelas A } 15 \mathrm{~cm} \\
\text { CBR tanah dasar } 6,2 \%\end{array}$ \\
\hline 5 & 5 & $60-67$ & $\begin{array}{c}\text { Lapisan AC-WC } 4 \mathrm{~cm} \\
\text { Lapisan AC-BC } 13,5 \mathrm{~cm} \\
\text { CTB } 15 \mathrm{~cm} \\
\text { LPA Kelas A } 15 \mathrm{~cm} \\
\text { CBR tanah dasar } 5,6 \%\end{array}$ \\
\hline 6 & 6 & $67-68$ & $\begin{array}{c}\text { Lapisan AC-WC } 4 \mathrm{~cm} \\
\text { Lapisan AC-BC } 13,5 \mathrm{~cm} \\
\text { CTB } 15 \mathrm{~cm} \\
\text { LPA Kelas A } 15 \mathrm{~cm} \\
\text { CBR tanah dasar } 5,1 \%\end{array}$ \\
\hline 7 & 7 & $68-76$ & $\begin{array}{c}\text { Lapisan AC-WC } 4 \mathrm{~cm} \\
\text { Lapisan AC-BC } 13,5 \mathrm{~cm} \\
\text { CTB } 15 \mathrm{~cm} \\
\text { LPA Kelas A } 15 \mathrm{~cm} \\
\text { CBR tanah dasar } 6,2 \%\end{array}$ \\
\hline 8 & 8 & $76-113+800$ & $\begin{array}{c}\text { Lapisan AC-WC } 4 \mathrm{~cm} \\
\text { Lapisan AC-BC } 13,5 \mathrm{~cm} \\
\text { CTB } 15 \mathrm{~cm} \\
\text { LPA Kelas A } 15 \mathrm{~cm} \\
\text { CBR tanah dasar } 5,2 \%\end{array}$ \\
\hline 9 & 9 & $113+800-115$ & $\begin{array}{c}\text { Lapisan AC-WC } 4 \mathrm{~cm} \\
\text { Lapisan AC-BC } 13,5 \mathrm{~cm} \\
\text { CTB } 15 \mathrm{~cm} \\
\text { LPA Kelas A } 15 \mathrm{~cm} \\
\text { LPB } 15 \mathrm{~cm} \\
\text { CBR tanah dasar } 4,1 \%\end{array}$ \\
\hline 10 & 10 & $115-118+200$ & $\begin{array}{c}\text { Lapisan AC-WC } 4 \mathrm{~cm} \\
\text { Lapisan AC-BC } 13,5 \mathrm{~cm} \\
\text { CTB } 15 \mathrm{~cm} \\
\text { LPA Kelas A } 15 \mathrm{~cm} \\
\text { CBR tanah dasar } 5,8 \%\end{array}$ \\
\hline
\end{tabular}

CBR tanah dasar $5,3 \%$

[1] Anonimous : Manual Desain Perkerasan

\section{KESIMPULAN}

Berdasarkan hasil penelitian diperoleh kesimpulan bahwa perencanaan tebal perkerasan jalan ruas Maros - Ujung Lamuru, pada segmen 9 perlu adanya peningkatan $\angle P B$ setebal $150 \mathrm{~mm}$ atau 15 $\mathrm{cm}$ karena nilai $C B R$ tanah dasarnya rendah. Tebal perkerasan dengan menggunakan Metode Bina Marga 2013 lebih ekonomis dan umur rencananya lebih lama dibandingkan dengan metode Analisa Komponen.

\section{DAFTAR PUSTAKA}


[4] Amima, I. 2011. Perencanaan Tebal Struktur Perkerasan Lentur Dan Rencana Anggaran Biaya Ruas Jalan ParinginMuara Pitap Kabupaten Balangan, Skripsi, Universitas Lambung Mangkurat, Banjarmasin.

[5] Massarrang, Haryanto, 2005, Alternatif Perencanaan Tebal Perkerasan Jalan dengan Metode AASHTO Pada Ruas Jalan Mameh - Bintuni Kabupaten Manokwari, Skripsi, Universitas Hasanuddin, Makassar.

[6] Morlok, Edward K, 1991, Pengantar Teknik dan Perencanaan Transportasi, Erlangga, Jakarta.

[7] Pongtuluran, Yosep dan Payung, Ganna Sartina, 2005, Alternatif Perencanaan
Tebal Perkerasan Ruas Jalan Tembus Hertasning Kotamadya Makassar dengan Metode US ARMY, Skripsi, Universitas Kristen Indonesia Paulus, Makassar.

[8] Pusat Penelitian dan Pembangunan Jalan Balitbang P.U, Pedoman Sederhana Pembangunan Prasarana Jalan dan Jembatan untuk Pedesaan, PT.Mediatama Saptakarya, Jakarta, 1996.

[9] Soedarsono, Untung Djoko, 1979, Konstruksi Jalan Raya, Direktorat Jendral Bina Marga Departemen Pekerjaan Umum, Jakarta Selatan.

[10] Sukirman, Silvia, 1999, Perkerasan Lentur Jalan Raya, Nova, Bandung. 